\title{
Differential protein clearances and response to treatment in Nigerian nephrotic children
}

\author{
A. ADENIYI, R. G. HENDRICKSE, ${ }^{\star}$ and J. F. SOOTHILL \\ From the Department of Paediatrics, University College Hospital, Ibadan, Nigeria and \\ Department of Immunology, Institute of Child Health, London
}

\begin{abstract}
Adeniyi, A., Hendrickse, R. G., and Soothill, J. F. (1976). Archives of Disease in Childhood, 51, 691. Differential protein clearances and response to treatment in Nigerian nephrotic children. Remission followed prednisolone therapy in 9 out of 21 Nigerian children with the nephrotic syndrome who had highly selective proteinuria $(\mathrm{Cg} / \mathrm{CA}<15 \%)$. Of these, 5 patients have remained well off all treatment during a follow-up of nearly 5 years, 4 have relapsed more than once but have responded to further courses of prednisolone. 3 of 21 with less selective proteinuria also remitted but all relapsed and only one of these has responded again. The other two have relapsed and further courses of prednisolone have not totally abolished their proteinuria though they are asymptomatic and in good health.

Toxicity (hypertension, sometimes with encephalopathy and infection) was commoner in the patients with less selective proteinuria treated with steroids than in those with highly selective proteinuria. 3 steroid-sensitive patients who had had repeated relapses became free from relapse off all treatment after a course of cyclophosphamide, given during steroid-maintained remission. All but 2 of the renal biopsies taken were regarded as abnormal. The lesions were less severe in those who responded than in those who did not. There is some evidence to suggest that Plasmodium malariae may be a cause of some of the steroid-sensitive disease, as well as the steroid-resistant.
\end{abstract}

Steroid therapy in Nigerian children with the nephrotic syndrome had led to little therapeutic benefit and severe side effects (Hendrickse and Gilles, 1963; Hendrickse, 1966; Adeniyi, Hendrickse, and Houba, 1970), so the routine use of prednisolone as a drug of first choice for them has been abandoned. It was noticed during the early trials, however, that a few responded quickly to steroid therapy, some remaining in prolonged remission while others soon relapsed.

It was necessary to identify the minority of children who were likely to benefit from steroid therapy without putting the majority at risk of hypertension, encephalopathy, severe infections, and sudden death which followed corticosteroid therapy in many of them. In a pilot study we reported that 2 children in relapse after previous steroid response had highly selective proteinuria, while the majority of the children with the nephrotic

Received 12 January 1976.

*Present address: Alder Hey Children's Hospital, Eaton Road, Liverpool L12 2AP. syndrome studied had poorly selective proteinuria (Soothill and Hendrickse 1967). We therefore measured differential protein clearance in new patients seen over a period of 2 years, arbitrarily separated them into groups with highly selective, moderately selective, and poorly selective proteinuria, and observed the effects of steroids in the first two groups.

\section{Patients and clinical findings}

100 Nigerian children ( $<12$ years) with the nephrotic syndrome were seen at the outpatient department of University College Hospital, Ibadan, over a 2-year period. They were selected because of generalized massive oedema, usually with ascites, heavy proteinuria, and serum albumin below $2.00 \mathrm{~g} / 100 \mathrm{ml}(20 \mathrm{~g} / \mathrm{l})$ $(<1.00 \mathrm{~g}$ in $90 \%)$. The peak age incidence was at 7 years; 7 were under 3 years of age, all boys; and the only child under 2 years died a few hours after admission. All had urinary casts, mainly granular and hyaline, but none had macroscopical haematuria, and only occasional red cells on urine microscopy. 4 were hypertensive (blood pressure $>120 / 80 \mathrm{~mm} \mathrm{Hg}$ ) when first seen, but azotaemia was exceptional. 
Differential protein clearance studies. Urine and plasma concentrations of albumin and IgG were measured by the single radial gel diffusion method (Fahey and McKelvey, 1965). The patients were arbitrarily divided into three groups by the clearance ratios of $\mathrm{IgG}$ to albumin $(\mathrm{CG} / \mathrm{CA})$. Those with values
$<15 \%$ were called highly selective, those between $16 \%$ and $30 \%$ moderately selective, and those $>30 \%$ poorly selective proteinuria. By chance the highly selective and moderately selective proteinuria groups were of the same size, 21 each. These patients were given prednisolone. The remaining 58 with poorly selective protein-

TABgE

Findings and outcome after steroid treatment in nephrotic childeren

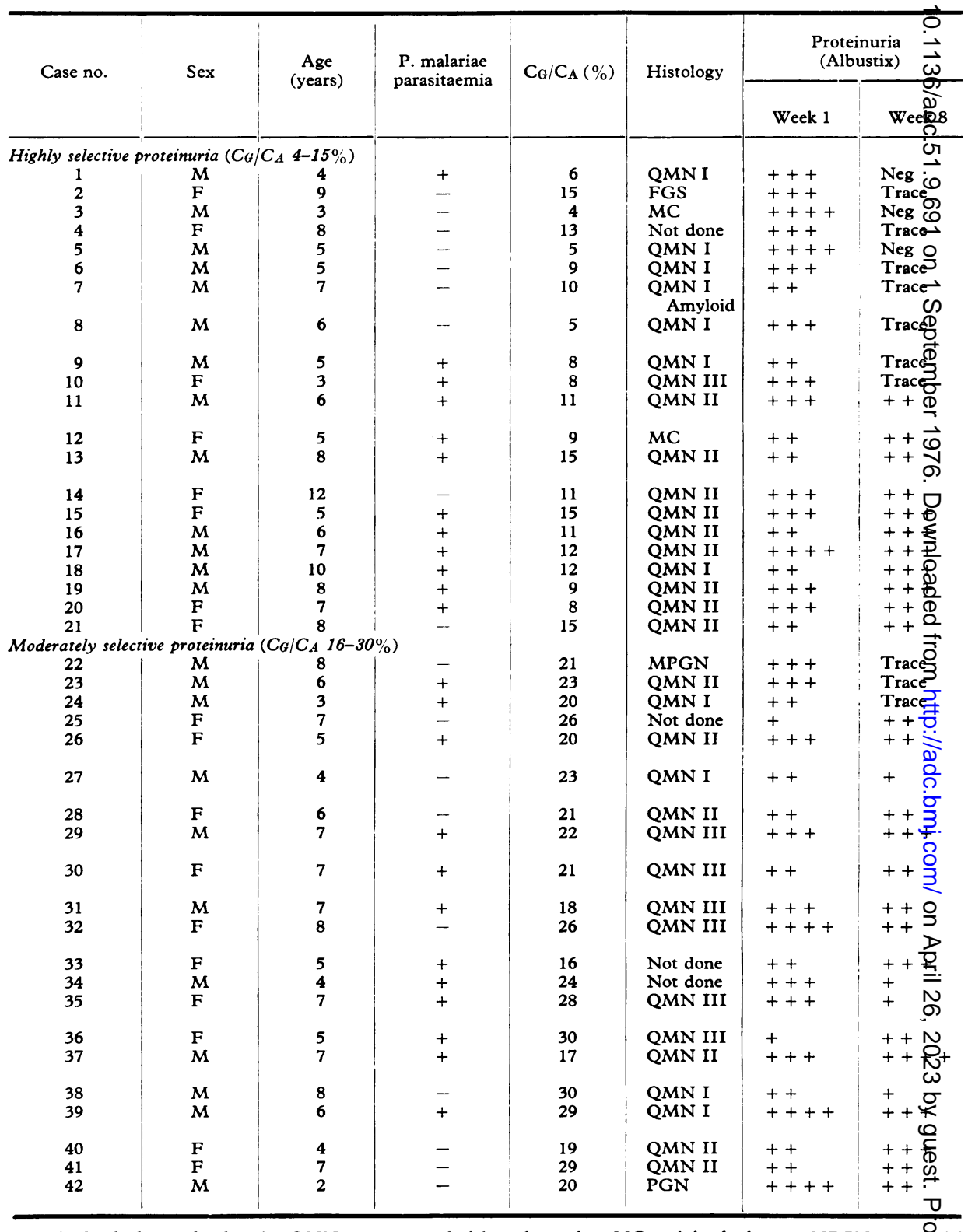


uria were not, and are not considered further in this paper. Their response to cytotoxic drugs will be published separately. The Table shows the clinical features, Plasmodium malariae parasitaemia, selectivity of proteinuria, renal biopsy histology, and response to treatment in the two groups treated with prednisolone.
Renal biopsies. As reported in detail elsewhere (Adeniyi, 1972; Hendrickse et al., 1972) the majority of renal biopsies from these patients showed histological abnormalities not seen in children with the nephrotic syndrome in temperate regions, and this peculiar lesion has been called quartan malarial nephropathy.

i Ibadan with highly selective and moderately selective proteinuria

\begin{tabular}{|c|c|c|c|c|}
\hline \multicolumn{2}{|c|}{ Plasma albumin $(\mathrm{g} / 100 \mathrm{ml})$} & \multicolumn{2}{|c|}{ Hypertension } & \multirow{2}{*}{ Outcome, complications, etc. } \\
\hline Week 1 & Week 8 & $\begin{array}{l}\text { Before } \\
\text { treatment }\end{array}$ & $\begin{array}{l}\text { During } \\
\text { treatment }\end{array}$ & \\
\hline $\begin{array}{l}0.83 \\
0 \cdot 64 \\
0 \cdot 34 \\
0 \cdot 69 \\
0 \cdot 89 \\
1 \cdot 10 \\
0.98\end{array}$ & $\begin{array}{l}2 \cdot 45 \\
2 \cdot 45 \\
3 \cdot 92 \\
3 \cdot 10 \\
2 \cdot 94 \\
2 \cdot 45 \\
1 \cdot 96\end{array}$ & $\begin{array}{l}- \\
- \\
- \\
- \\
-\end{array}$ & $\begin{array}{l}- \\
- \\
- \\
- \\
-\end{array}$ & $\begin{array}{l}\text { Sustained remission } \\
\text { Sustained remission } \\
\text { Sustained remission } \\
\text { Sustained remission } \\
\text { Sustained remission } \\
\text { Bronchopneumonia; relapsed after } 6 \mathrm{~m} \\
\text { Relapsed after } 3 \mathrm{~m}\end{array}$ \\
\hline $0 \cdot 88$ & $2 \cdot 50$ & - & - & $\begin{array}{l}\text { Relapsed after } 1 \text { year; bronchopneumonia, skin } \\
\text { infections }\end{array}$ \\
\hline $\begin{array}{l}0.98 \\
1 \cdot 32\end{array}$ & $\begin{array}{l}2 \cdot 45 \\
3 \cdot 64\end{array}$ & $\underline{-}$ & $\overline{-}$ & $\begin{array}{l}\text { Relapsed after } 10 \mathrm{~m} \\
\text { Persistent proteinuria }\end{array}$ \\
\hline 0.61 & $1 \cdot 96$ & + & + & $\begin{array}{l}\text { Persistent proteinuria; hypertension, convulsions; } \\
\text { encephalopathy }\end{array}$ \\
\hline $0 \cdot 64$ & $2 \cdot 45$ & - & - & Persistent proteinuria \\
\hline $0 \cdot 20$ & $2 \cdot 94$ & - & - & $\begin{array}{l}\text { Persistent proteinuria; bronchopneumonia; skin } \\
\text { infections }\end{array}$ \\
\hline 0.88 & 0.61 & + & + & Encephalopathy coma; dead \\
\hline $1 \cdot 67$ & $\begin{array}{l}1 \cdot 64 \\
1 \cdot 32\end{array}$ & $\overline{-}$ & - & Persistent proteinuria \\
\hline $\begin{array}{l}0 \cdot 74 \\
1 \cdot 52\end{array}$ & $\begin{array}{l}1 \cdot 32 \\
2 \cdot 45\end{array}$ & - & $\begin{array}{l}+ \\
+\end{array}$ & $\begin{array}{l}\text { Persistent hypertension + proteinuria; dead } \\
\text { Persistent proteinuria; hypertension; dead }\end{array}$ \\
\hline $1 \cdot 76$ & $2 \cdot 96$ & - & - & Persistent proteinuria \\
\hline $1 \cdot 54$ & $1 \cdot 61$ & - & - & Persistent proteinuria \\
\hline 0.83 & 0.83 & - & - & Persistent proteinuria \\
\hline $1 \cdot 08$ & $0 \cdot 83$ & - & + & Convulsions, hypertension, dead $2 \mathrm{~m}$ \\
\hline $0 \cdot 22$ & $2 \cdot 35$ & - & - & Bronchopneumonia; tuberculosis; relapsed $3 \mathrm{~m}$ \\
\hline $\begin{array}{l}0 \cdot 37 \\
1 \cdot 23\end{array}$ & $\begin{array}{l}2 \cdot 16 \\
2 \cdot 94\end{array}$ & $\overline{-}$ & $\overline{+}$ & $\begin{array}{l}\text { Relapsed } 3 \mathrm{w} \\
\text { Relapsed } 4 \mathrm{~m} \text {; dead }\end{array}$ \\
\hline $1 \cdot 32$ & $2 \cdot 15$ & - & + & Persistent proteinuria; hypertension \\
\hline $1 \cdot 23$ & $1 \cdot 96$ & - & + & $\begin{array}{l}\text { Bronchopneumonia; persistent proteinuria; } \\
\text { hypertension }\end{array}$ \\
\hline $1 \cdot 23$ & $2 \cdot 13$ & - & + & $\begin{array}{l}\text { Persistent proteinuria; hypertension; } \\
\text { bronchopneumonia }\end{array}$ \\
\hline $1 \cdot 23$ & $1 \cdot 59$ & - & + & Persistent hypertension; dead \\
\hline 0.33 & $1 \cdot 65$ & + & + & $\begin{array}{l}\text { Bronchopneumonia; persistent proteinuria; } \\
\text { hypertension; dead }\end{array}$ \\
\hline $1 \cdot 72$ & $1 \cdot 27$ & - & - & $\begin{array}{l}\text { Persistent proteinuria; subsequent hypertension; } \\
\text { dead }\end{array}$ \\
\hline 0.61 & $2 \cdot 01$ & - & + & Persistent proteinuria; hypertension; dead \\
\hline 0.61 & $0 \cdot 88$ & - & - & $\begin{array}{l}\text { Bronchopneumonia, skin infections, persistent } \\
\text { proteinuria; dead }\end{array}$ \\
\hline $0 \cdot 31$ & & - & - & Persistent proteinuria; dead \\
\hline 0.91 & $1 \cdot 21$ & - & - & Persistent proteinuria \\
\hline $1 \cdot 42$ & $1 \cdot 23$ & + & + & $\begin{array}{l}\text { Persistent proteinuria; bronchopneumonia; } \\
\text { hypertension; dead }\end{array}$ \\
\hline $2 \cdot 45$ & $2 \cdot 94$ & - & + & Persistent proteinuria; hypertension; dead \\
\hline 0.62 & 0.67 & + & + & $\begin{array}{l}\text { Persistent proteinuria; bronchopneumonia; } \\
\text { infections; hypertension; dead }\end{array}$ \\
\hline $1 \cdot 42$ & $1 \cdot 25$ & - & + & Persistent proteinuria; hypertension; dead \\
\hline $0 \cdot 94$ & $1 \cdot 15$ & - & + & $\begin{array}{l}\text { Bronchopneumonia, persistent proteinuria, } \\
\text { hypertension; dead }\end{array}$ \\
\hline 0.64 & $1 \cdot 23$ & - & - & Persistent proteinuria \\
\hline $1 \cdot 37$ & $1 \cdot 62$ & - & - & Persistent proteinuria \\
\hline $1 \cdot 61$ & $3 \cdot 23$ & - & + & Bronchopneumonia; persistent proteinuria \\
\hline
\end{tabular}


Only 5 had lesions classifiable by the criteria of the International Study of Kidney Disease in Children (Churg, Habib, and White, 1970)-2 with minimal change and one each with focal glomerulosclerosis, proliferative glomerulonephritis, and mesangial proliferative glomerulonephritis.

The characteristic lesion of quartan malarial nephropathy is thickening of the glomerular capillary walls, which may be segmental at first. The subendothelial aspect of the basement membrane is usually affected, giving rise to double contour or plexiform arrangement of PAS-positive argyrophilic fibrils. Progressive sclerosis occurs, which leads to narrowing and obliteration of the capillaries. Tubular lesions are proportional in extent to glomerular damage to which they may be secondary. Mesangial cellular proliferation is not a prominent feature but localized areas of hypercellularity are occasionally seen.

The quartan malarial nephropathic lesions were graded according to the severity of the lesions as follows. Grade I, capillary wall thickening and segmental sclerosis in $<30 \%$ of glomeruli. Grade II, 30-75\% of glomeruli affected; more severe diffuse capillary wall thickening and sclerosis. Grade III, $>75 \%$ of glomeruli affected; extensive sclerosis, marked plexiform thickening of the capillary walls and obliteration of the lumens.

\section{Treatment}

All patients received high protein and low sodium diet with vitamin supplement. Oral chloroquine (4-amino quinoline) and primaquine (8-amino quinolone) were given to eradicate parasites both in the blood and the tissues. All had the diuretic hydroflumethiazide plus potassium chloride (for details see Adeniyi et al., 1970). Antibiotics were given for skin or respiratory infections present in a few cases and these general measures were used alone for 2-3 weeks after the first visit to the hospital. No remissions occurred during this period.

Prednisolone was given orally $2 \mathrm{mg} / \mathrm{kg}$ per day for 4 weeks then reduced to $1.5 \mathrm{mg} / \mathrm{kg}$ per day for 3 consecutive days a week for a further 4 weeks, after which the drug was discontinued.

The effect of treatment was assessed by the loss of oedema and also by the reduction in proteinuria as shown by Albustix tests on random urine samples at the beginning and end of steroid therapy. The level of serum albumin was also measured. Albustix test of trace or negative was associated in most cases with significant rise in serum albumin levels at the end of 8 weeks of prednisolone therapy in those who responded well.

\section{Results}

Good remission, indicated by the disappearance of oedema and proteinuria (Albustix trace or negative) accompanied by a rise in serum albumin level to $>2.00 \mathrm{~g} / 100 \mathrm{ml}(20 \mathrm{~g} / \mathrm{l})$ was observed in 9 out of 21 children with highly selective proteinuria, but in only 3 of the 21 with moderately selective pro- teinuria. This difference is significant on Fisher's exact test $(P<0 \cdot 05)$. 3 others with highly selective proteinuria lost their oedema and serum albumin rose to $2.00 \mathrm{~g} / 100 \mathrm{ml}$ or above, but proteinuria $(+)$ persisted. In all these there was a big fall in albumin clearance. Serum albumin also rose and oedema cleared in most of the remaining patients but they all had persistent heavy proteinuria (albustix $2+$ to $4+$ ). Of the patients with highly selective proteinuria, only 2 of the 9 who responded completely had $P$. malariae parasitaemia, whereas it was present in 10 of the 12 who did not respond, a significant difference in parasitaemia rate in the two groups $(P<0.01)$. The 3 children with moderately selective proteinuria who had complete remissions all relapsed later and only one responded well to a further course of prednisolone; 3 others improved, but heavy proteinuria persisted in the remaining 15 .

Toxicity of corticosteroid therapy. Hypertension (defined as blood pressure of $120 / 80 \mathrm{mmHg}$ and above) was the most serious toxic effect of steroid therapy. 5 children with highly selective proteinuria were hypertensive during steroid therapy and all had convulsions. 2 of these had been hypertensive before treatment but their blood pressures were reduced to normal levels with reserpine before prednisolone treatment was started. One of them died in coma after convulsions and the other had persistent hypertension. In the other 3 the blood pressure returned to normal levels within 6 weeks of withdrawal of prednisolone. 3 in this group developed bronchopneumonia.

Three of the 21 with moderately selective proteinuria were hypertensive before prednisolone treatment but 13 became hypertensive during it and this was significantly more frequent than in the group with highly selective proteinuria $(P<0 \cdot 05)$. 4 of them developed hypertensive encephalopathy with coma and convulsions and one died. Blood pressure values appeared to return to normal more slowly (8-12 weeks) after withdrawal of prednisolone than in the patients with highly selective proteinuria, and hypertension which developed during steroid treatment has persisted in 4. One had recrudescence of quiescent tuberculosis and 9 had bronchopneumonia.

Relapses. 5 of the 9 responders in the group with highly selective proteinuria have remained in stable remission for over 4 years. The remaining 4 have relapsed often and needed further courses of prednisolone. Response has become less prompt and complete; low levels of proteinuria (Albustix $>$ 
trace to $2+$ ) persist in all 4 . The 3 who responded among those with moderately selective proteinuria have relapsed, and only one (Case 22) has continued to respond fully after repeated courses of prednisolone; the other 2 have persistent proteinuria (Albustix + or $2+$ ).

Three children, including 2 from this series (Cases 6 and 22), who had relapsed frequently on withdrawal of prednisolone, have been treated with cyclophosphamide $3 \mathrm{mg} / \mathrm{kg}$ for 8 weeks (Barratt and Soothill, 1970) during steroid-maintained remission, after which all treatment was withdrawn. Case 6 first had the nephrotic syndrome $3 \frac{1}{2}$ years previously and responded to steroids repeatedly, but relapsed 3 times within a year; he has remained well without proteinuria for over 5 months, after cyclophosphamide. Case 22 had a number of features of special interest. He had four episodes of nephrotic syndrome during 3 years each one of which responded to prednisolone. He had moderately selective proteinuria $\left(\mathrm{CG} / \mathrm{CA}_{\mathrm{a}}=21 \%\right)$ and renal biopsy showed grade I quartan malarial nephropathy. He had $P$. malariae parasitaemia and $P$. malariae antigen, IgG and $B_{1} c$ were detected in the kidney by immunofluorescence (Houba et al., 1970). He has been free of proteinuria for over 2 years after cyclophosphamide treatment. The third patient, one of the 2 steroid-sensitive relapsing patients reported by Soothill and Hendrickse (1967), had had 4 or 5 relapses each year for 6 years, and required increasing doses of prednisolone to control relapses. He was given cyclophosphamide, and is now well with no proteinuria 3 years after withdrawal of all treatment. He had highly selective proteinuria ( $\mathrm{CG} / \mathrm{CA}=9 \%$ ), minimal renal histological changes, and no $P$. malariae parasitaemia.

\section{Discussion}

The clinical features of the patients studied were similar to previous reports of nephrotic children in Ibadan, except that the peak age was older (Hendrickse and Gilles, 1963). The disappearance of proteinuria in the minority of patients clearly resulted from the steroid treatment in most of them because it followed within 4 to 6 weeks of treatment; a slower fall in proteinuria was also seen in some others. A few had substantial reduction of proteinuria with rise in serum albumin to normal levels, but without complete loss of proteinuria; this may also be an effect of steroid treatment, though spontaneous improvement, and effects of diet and general measures may also have contributed. Such a partial response is not recognized in nephrotic children from temperate regions, though it has been described in Delhi where malaria is rare (Chandra et al., 1970). The rest had persistent and heavy proteinuria and there was no appreciable or sustained rise in serum albumin.

Using our arbitrarily chosen limit of $\mathrm{CG} / \mathrm{CA}$ of $15 \%$, all 5 patients with sustained steroid remission, and probably all but 3 who responded but relapsed were identified, assuming that none of the poorly selective group would have responded. Nearly half of those who satisfied this possible method of selection for treatment did not respond, but toxicity was only occasionally a serious problem for them. The simple test of differential protein clearances has therefore provided a means of identifying those of our patients most likely to benefit from steroid therapy, without resorting to routine use of corticosteroids, which may be disastrous in many cases.

In temperate areas renal biopsy permits the identification of most steroid-sensitive patientsthose with minimal glomerular abnormality. Such findings were detected in only 2 of our patients, most of whom had definite histological lesions, sometimes severe. Only 3 were classifiable in terms used in temperate areas. The rest, which have been described in detail elsewhere, are classified as quartan malarial nephropathy grades I-III (Edington and Mainwaring 1966, Hendrickse et al., 1972). The greater risk of steroid toxicity in Nigerian nephrotic children as compared with those from the temperate regions to some extent parallels experience with adult nephrotics in temperate regions. This is therefore consistent with the belief that the different underlying diseases, which include more of those which induce hypertension, may be the explanation. However associated, nutritional, infective, and care problems could also contribute to this difference.

Good steroid response may be expected in most cases with mild histological damage whether this is described as minimal changes, or as quartan malaria nephropathy grade I. In most of those with highly selective proteinuria and severe morphological abnormalities, there was little or no response to corticosteroids.

In 3 patients in whom repeated relapses had occurred over 3 or more years treatment with cyclophosphamide during steroid-induced remission has produced prolonged remission without overt toxicity, as reported in Britain (Barratt and Soothill, 1970). Both these recent advances in management of nephrotic children can therefore be applied to the minority in Nigeria for whom they are appropriate.

The association between differential protein clearance data and $P$. malariae parasitaemia in a larger series will be reported separately. There is a 
trend in this series which is not significant, for parasitaemia to be less common in those who responded than in those who did not, suggesting that though $P$. malariae is the probable cause of most of the latter, other causes may exist in the former. Since steroid-sensitive disease with highly selective proteinuria forms only a minority of nephrotic children in Delhi, where malaria is rare (Chandra et al., 1970), other infections which do not occur in temperate areas may also contribute aetiologically. It is interesting that steroid responders have an incidence of $P$. malariae parasitaemia probably higher than in the general population at this age. The mild form of the histological renal lesion regarded as characteristic of quartan nephropathy was found, in the presence of $P$. malariae antigen, IgG, and $\mathrm{C} 3$ deposits, in one patient (Case 22) who responded to prednisolone treatment. This finding suggests this antigen may be able to induce steroid-responsive nephrotic syndrome, for which there is some evidence of immunopathogenesis (Ngu, Barratt, and Soothill, 1969), as well as the more usual steroid-resistant disease. If this is so, this represents the second antigen known to do so (Hardwicke et al., 1959). The nature of the postulated immunopathological damage in these patients is not yet known. The possibility of coincidence cannot be excluded, but it suggests that different forms of renal damage can be elicited by the same antigens, the nature of the damage presumably depending on the individual's immune response (Soothill and Steward, 1971).

The higher incidence of steroid toxicity in the poorly selective group than in the highly selective group indicated that this toxicity is partly disease related, perhaps due to increased response to a hypertensive stimulus. Our results confirm previous impressions that steroids are useless and damaging to most nephrotic children in Ibadan, and differential protein clearance measurements permit us to select patients for this treatment. The arbitrarily selected value of $\mathrm{CG} / \mathrm{CA}$ of $15 \%$ used in this study for identifying patients for treatment is not necessarily ideal, but our data suggest that it is an acceptable first approximation. More experience will be needed to assess this precisely, perhaps using more or other proteins.
We are grateful to Professor Houba, and Drs. R. H. R. White and E. F. Glasgow for advice and for immunofluorescence and histological classifications; and to the Wellcome Foundation for financial support.

\section{REFERENCES}

Adeniyi, A. (1972). The nephrotic syndrome in Nigerian children. M.D. thesis, University of London, p. 55.

Adeniyi, A., Hendrickse, R. G., and Houba, V. (1970). Selectivity of proteinuria and response to prednisolone or immunosuppressive drugs in children with malarial nephrosis. Lancet, 1 , 644.

Barratt, T. M., and Soothill, J. F. (1970). Controlled trial of cyclophosphamide in steroid-sensitive relapsing nephrotic syndrome of childhood. Lancet, 2, 479.

Chandra, R. K., Manchanda, S. S., Srivastava, R. N., and Soothill, J. F. (1970). Differential protein clearances in Indian children with the nephrotic syndrome. Archives of Disease in Childhood, 45, 491.

Churg, J., Habib, R., and White, R. H. R. (1970). Pathology of the nephrotic syndrome in children. A report for the international study of kidney disease in children. Lancet, 1, 1299.

Edington, G. M., and Mainwaring, A. R. (1966). Nephropathies in West Africa. The Kidney, Chap. 24. Ed. by F. K. Mostofi and D. E. Smith. Williams and Wilkins, Baltimore.

Fahey, J. L., and McKelvey, E. M. (1965), Quantitative determination of serum immunoglobulins in antibody-agar plates. fournal of Immunology, 94, 84.

Hardwicke, J., Soothill, J. F., Squire, J. R., and Holti, G. (1959). Nephrotic syndrome with pollen hypersensitivity. Lancet, $1,500$.

Hendrickse, R. G. (1966). Proceedings of the 3rd International Congress of Nephrology, p. 208 . Ed. by G. E. Schreiner. Karger, Basel.

Hendrickse, R. G., and Gilles, M. (1963). The nephrotic syndrome and other renal disease in children in Western Nigeria. East African Medical fournal, 40, 186.

Hendrickse, R. G., Glasgow, E. F., Adeniyi, A., White, R. H. R., Edington, G. M., and Houba, V. (1972). Quartan malarial nephrotic syndrome. Collaborative clinicopathological study in Nigerian children. Lancet, 1, 1143.

Houba, V., Allison, A. C., Hendrickse, R. G., de Petris, S., Edington, G. M., and Adeniyi, A. (1970). Immune complexes in the nephrotic syndrome of Nigerian children. Proceedings of the International Symposium on Immune Complex Diseases, p. 23. Ed. by L. Bonomo and J. L. Turk. Carlo Erba Foundation, Milan.

Ngu, J. L., Barratt, T. M., and Soothill, J. F. (1969). Immunoconglutinin and complement changes in children with acute nephritis. Clinical and Experimental Immunology, 5, 557.

Soothill, J. F., and Hendrickse, R. G. (1967). Some immunological studies of the nephrotic syndrome of Nigerian children. Lancet, $2,629$.

Soothill, J. F., and Steward, M. W. (1971). The immunopathological significance of the heterogeneity of antibody affinity. Clinical and Experimental Immunology, 9, 193.

Correspondence to Prof. J. F. Soothill, Department of Immunology, Institute of Child Health, 30 Guilford Street, London WCIN IEH. 